\title{
Editorial: Commemorating computer chess
}

\author{
Mark Winands* \\ Department of Data Science and Knowledge Engineering, Maastricht University, The Netherlands
}

It has taken some time to produce this issue, but it will be truly a special and historical one! It is a double issue consisting out of two parts, fully devoted to computer chess. The first part is the special issue on fifty years of computer chess. Our president, Jonathan Schaeffer, acts as the guest editor here. Besides his own contribution, there will be eight other articles in this part. They are written by David Slate, Tony Marsland, Monty Newborn, David Levy, Linda Scherzer, Robert Hyatt, Ulf Lorenz, and Ingo Althöfer amongst others. In the editorial of the special issue, Jonathan gives a proper introduction of all the contributions.

The second part consists out of contributions also devoted to the history of computer chess. Guy Haworth kicks off with his note Thomas Ströhlein's endgame tables, a 50th anniversary. It celebrates Ströhlein's Ph.D. thesis Untersuchungen über kombinatorische Spiele, which described the first implementation of retrograde analysis resulting in the creation of the KRk, KQk, KRkb, KRkn, and KQkr endgame databases. Next, there is the contribution A program for analyzing two move chess problems by the late Dieter Müller, who passed away in 2019. It reports about an almost forgotten attempt to find themes in chess composition automatically by machine. The article is based on an unpublished manuscript by him from 1979, which was revised by Michael Schlosser, Rainer Staudte, and Christian Posthoff for this issue. The last say is by Monty Newborn, who reflects back on the history of computer chess in The laughing is over.

Finally, this issue also highlights the achievements of the computer chess engines participating in TCEC 17, TCEC 18, TCEC Cup 5, and TCEC Cup 6. It also gives an updated SSDF rating list. This one is in remembrance of Tony Hedlund, a tester and administrator of the SSDF database of test games, who passed away in 2019.

I would like to thank everybody who contributed to this memorable issue. Especially, Jonathan Schaeffer has made a tremendous effort in getting a strong line-up of contributors. I hope everybody will enjoy reading this double issue!

Mark Winands

\footnotetext{
*E-mail: m.winands@maastrichtuniversity.nl.
} 